\title{
Increased prevalence of sleep disturbances and daytime sleepi- ness in subjects with bronchial asthma: a population study of young adults in three European countries
}

\author{
C. Janson*+, W. De Backer**, T. Gislason++, P. Plaschke\#, E. Björnsson*, J. Hetta\#\#, \\ H. Kristbjarnarson+, P. Vermeire**, G. Boman*
}

Increased prevalence of sleep disturbances and daytime sleepiness in subjects with bronchial asthma: a population study of young adults in three European countries. C. Janson, W. De Backer, T. Gislason, P. Plaschke, E. Björnsson, J. Hetta, H. Kristbjarnarson, P. Vermeire, G. Boman. (C) ERS Journals Ltd 1996.

ABSTRACT: The aim of this study was to investigate whether asthma is associated with decreased quality of sleep and increased daytime sleepiness.

The study involved a random population of 2,202 subjects supplemented by 459 subjects with suspected asthma, aged 20-45 yrs. The subjects were from Reykjavik (Iceland), Uppsala and Göteborg (Sweden) and Antwerp (Belgium), and participated in the European Community Respiratory Health Survey. The investigation included a structured interview, methacholine challenge, skinprick tests and a questionnaire on sleep disturbances. Participants in Iceland and Sweden also estimated their sleep times and made peak expiratory flow (PEF) recordings during a period of 1 week. Asthma was defined as self-reported physician-diagnosed asthma with current asthma-related symptoms $(n=267)$.

Difficulties inducing sleep (DIS) and early morning awakenings (EMA) were about twice as common, and daytime sleepiness $\mathbf{5 0 \%}$ more common, in asthmatics compared with subjects without asthma. After adjusting for possible confounders, a positive association was found between asthma and: DIS (odds ratio $(O R)=1.8)$; EMA $(O R=2.0)$; daytime sleepiness $(O R=1.6)$; snoring $(O R=1.7)$; and self reported apnoeas $(\mathrm{OR}=3.7)$. Allergic rhinitis, which was reported by $71 \%$ of subjects with asthma, was independently related to DIS $(O R=2.0)$ and daytime sleepiness $(\mathrm{OR}=1.3)$. A significant correlation was found between the number of asthma-related symptoms and sleep disturbances $(\mathbf{p}<0.001)$.

Asthma is associated with decreased subjective quality of sleep and increased daytime sleepiness. Concurrent allergic rhinitis may be an important underlying cause of sleep impairment in asthmatic patients.

Eur Respir J., 1996, 9, 2132-2138.
* Dept of Lung Medicine and Asthma Research Centre, and \#"Sleep Unit, Dept of Psychiatry, Akademiska sjukhuset, Uppsala, Sweden. +Dept of Public Health Medicine, United Medical and Dental Schools, St Thomas's Hospital, London, UK. **Dept of Respiratory Medicine, University of Antwerp (UIA), Antwerp, Belgium. ${ }^{++}$Dept of Lung Medicine, Vifilsstadir Hospital, Gardabaer, Iceland. \#Asthma and Allergy Research Centre, Sahlgrenska Hospital, Göteborg, Sweden. +Dept of Psychiatry, University Hospital, Reykjavik, Iceland.

Correspondence: C. Janson, Dept of Public Health Medicine, St Thomas's Hospital, London SE1 7EH, UK

Keywords: Allergic rhinitis, asthma, bronchial hyperresponsiveness, epidemiology, sleep, snoring

Received: March 221996

Accepted after revision July 141996

This study was financially supported by the Swedish Heart and Lung Foundation, the Swedish Medical Research Council, the Swedish Association against Asthma and Allergy, the Swedish Society of Medicine, the Herman Krefting Foundation, the Bror Hjerpstedt Foundation and the County Council of Uppsala and Göteborg. The Belgian part of the study was supported by the Belgian Science Policy Office and the National Fund for Scientific Research.
Recent studies indicate that the prevalence of asthma in adults in northern Europe may now be as high as $5-8 \%$ [1-3]. Many patients with asthma experience symptoms at night $[4,5]$ and several studies have shown that the quality of sleep in such patients is decreased [6-8]. Studies from general population samples have also found that subjects with asthma have a decreased quality of sleep when compared with subjects without asthma [9-12]. The results of these studies are, however, somewhat contradictory, as increased daytime sleepiness in asthmatics has been found in some investigations [9-11], but not in the most recent population study [12]. A possible disadvantage in previous population studies on asthma and sleep disturbances is that they have been based only on questionnaire findings and have not included objective measurements.

Between 1990 and 1993, an epidemiological investigation into the prevalence of asthma and allergy, The European Community Respiratory Health Survey (ECRHS), was conducted in different centres throughout the world [13]. In the first part of this study, a large population of randomly selected adults, in the age range $20-44 \mathrm{yrs}$, answered a postal questionnaire. The second and more extensive part comprised a random sample of the first population supplemented by subjects for whom the postal questionnaire indicated suspected asthma. In four of the participating centres: Reykjavik in Iceland, Uppsala and Göteborg in Sweden, and Antwerp in Belgium, a questionnaire relating to sleep disturbances was added to the second part of the ECRHS study. One purpose of this questionnaire was to compare the prevalence of sleep complaints in randomly selected populations from different countries using the same methodology [14, 15].

The aim of the present investigation was to study the possible association between asthma and quality of sleep. A secondary aim was to assess possible underlying mechanisms that may cause an impaired quality of sleep in subjects with asthma. 


\section{Population and methods}

\section{Study areas and target populations}

The subjects in this study came from four centres: 1) Reykjavik, the capital of Iceland, and surrounding suburbs, with an approximate population of 160,$000 ; 2$ ) Uppsala, the fourth largest city in Sweden, with approximately 170,000 inhabitants; 3) Göteborg, the second largest city in Sweden. The study area comprised the northern part of the city on the island of Hisingen, with an approximate population of 110,000; and 4) Antwerp, the second largest city in Belgium. The study area comprised the centre of the city and 13 municipalities in the southern suburban area, with a target population of 300,000 inhabitants from a total of approximately 750,000.

\section{Populations}

In phase one of the ECRHS, a random sample, in the age range 20-44 yrs, was selected using the population register at each centre (fig. 1). A postal questionnaire was sent to all subjects. The number of subjects selected was 3,600 in Reykjavik, Uppsala and Göteborg and 8,029 in Antwerp, and the response rate to the questionnaire was $81,87,80$ and $75 \%$, respectively. A random sample of those answering the questionnaire in Reykjavik ( $\mathrm{n}=800)$, Uppsala $(\mathrm{n}=705)$ Göteborg $(\mathrm{n}=772)$ and Antwerp $(n=1,665)$ was invited to participate in the second phase of the study. This phase included a structured interview, measurement of lung function and allergy testing. The number of subjects who participated in the second phase of the study was $570(71 \%), 623$ (88\%), 682 (88\%) and 1,121 (67\%) in Reykjavik, Uppsala, Göteborg and Antwerp, respectively. A further sample of all the subjects who, in the postal questionnaire, reported nocturnal attacks of breathlessness, attacks of asthma or current use of medication for asthma was also selected for this further study: Reykjavik n=90, Uppsala n=216, Göteborg n=226 and Antwerp n=230 (fig. 1). The informed consent of all participants was obtained and the study was approved by all the Ethics Committees involved.

The screening questionnaire and the questionnaire used in the structured interview were based on the International Union Against Tuberculosis and Lung Disease (IUATLD) questionnaire $[13,16]$. In the interview, the patients answered questions relating to respiratory symptoms, respiratory disorders, medication and environmental factors. Asthma was defined as reporting: 1) ever having had asthma where the diagnosis had been confirmed by a doctor; and 2) having at least one asthmarelated symptom in the last 12 months.

Asthma related symptoms were defined as reporting: 1) wheezing or whistling in the chest; 2) wheezing in combination with breathlessness, and wheezing when not having a cold; or 3 ) having had an attack of shortness of breath that came during the day when at rest, or following strenuous activity. The number of asthmarelated symptoms reported was used for calculating an asthma symptom score.

Allergic rhinitis was defined as reporting having nasal allergy including hay fever.

\section{Lung function and bronchial hyperresponsiveness}

Forced expiratory volume in one second (FEV1) was measured in 2,167 persons using the Spiro Medics computerized dry-rolling seal spirometer system 2130 (Sensor Medics, Anaheim, CA, USA). The predicted values were calculated for each patient [17].

Methacholine challenge was performed in 1,980 individuals using a Mefar dosimeter (Mefar, Brescia, Italy) [18]. Patients with a decrease in FEV1 of $20 \%$ with an accumulated methacholine dose of $\leq 2 \mathrm{mg}$ were defined as having bronchial hyperresponsiveness (BHR) [19, 20].

All the participants in Uppsala and Göteborg and a random sample of $25 \%$ of the participants in Reykjavik,

\begin{tabular}{|c|c|c|c|c|}
\hline & $\begin{array}{l}\text { Reykjavik } \\
\text { Iceland }\end{array}$ & $\begin{array}{l}\text { Uppsala } \\
\text { Sweden }\end{array}$ & $\begin{array}{l}\text { Göteborg } \\
\text { Sweden }\end{array}$ & $\begin{array}{l}\text { Antwerp } \\
\text { Belgium }\end{array}$ \\
\hline \multirow{2}{*}{$\begin{array}{l}\text { Screening } \\
\text { questionnaire }\end{array}$} & 3,600 & 3,600 & 3,600 & 8029 \\
\hline & $\downarrow$ & $\downarrow$ & $\downarrow$ & $\downarrow$ \\
\hline \multirow{2}{*}{$\begin{array}{l}\text { Answered } \\
\text { questionnaire }\end{array}$} & $2,903(81 \%)$ & $3,147(87 \%)$ & $2,884(80 \%)$ & 6,027 (75\%) \\
\hline & $\downarrow$ & $\downarrow$ & $\downarrow$ & $\downarrow$ \\
\hline $\begin{array}{l}\text { Random + symptomatic } \\
\text { sample }\end{array}$ & $\begin{array}{c}800+90 \\
\downarrow\end{array}$ & $\begin{array}{c}705+216 \\
\downarrow \\
\downarrow\end{array}$ & $\begin{array}{c}772+226 \\
\downarrow \\
\downarrow\end{array}$ & $\begin{array}{c}1,665+230 \\
\downarrow \\
\downarrow\end{array}$ \\
\hline \multirow[t]{2}{*}{$\begin{array}{l}\text { Participated } \\
\text { in study }\end{array}$} & $\begin{array}{l}570+84 \\
(71+93 \%)\end{array}$ & $\begin{array}{l}623+201 \\
(88+93 \%)\end{array}$ & $\begin{array}{l}682+184 \\
(88+81 \%)\end{array}$ & $\begin{aligned} 1,121 & +162 \\
(67 & +70 \%)\end{aligned}$ \\
\hline & $\downarrow \downarrow$ & $\downarrow \quad \downarrow$ & $\downarrow \downarrow$ & $\downarrow \downarrow \downarrow$ \\
\hline $\begin{array}{l}\text { Answered sleep } \\
\text { questionnaire }\end{array}$ & $\begin{array}{l}535+78 \\
(94+93 \%)\end{array}$ & $\begin{array}{l}542+182 \\
(87+91 \%)\end{array}$ & $\begin{array}{l}426+114 \\
(62+62 \%)\end{array}$ & $\begin{array}{l}699+85 \\
(62+53 \%)\end{array}$ \\
\hline
\end{tabular}

Fig. 1. - Population selection and participation rates. In total, 2,202 of the random sample, and 459 of the symptomatic sample, answered the sleep questionnaire. 
and all of those with symptoms indicating asthma were asked to record peak expiratory flow (PEF) (the best of three measurements) twice daily for 1 week with a miniWright peak flow meter (Clement Clarke, London, UK). The number of patients who managed to record PEF measurements twice a day on at least 4 of 7 days was 155 in Reykjavik, 552 in Uppsala and 533 in Göteborg. PEF variability was calculated by dividing the difference between the highest and lowest daily PEF reading by the daily mean PEF value [21].

\section{Allergy testing}

Skin-prick test with the Phazet (Pharmacia Diagnostics, Uppsala, Sweden) was conducted on 2,144 individuals. Individuals with a positive prick test (weal with a mean diameter of $\geq 3 \mathrm{~mm}$ ) to at least one of the following allergens: birch, timothy, mugwort, Dermatophagoides pteronyssinus, cat, dog, Cladosporium herbatum or Alternaria alternata were defined as having atopy $[19,20]$. Individuals with a positive skin-prick test to $D$. pteronyssinus were defined as being house dust mite sensitive.

\section{Sleep questionnaire}

After completing the interview and examination, all the subjects were asked to fill in a separate questionnaire addressing their quality of sleep during the last few months. The questionnaire was a slightly modified version of a questionnaire used in previous Swedish and Icelandic studies $[10,11,22]$. The questionnaire, which has been described in detail in a previous paper [15], comprised 16 questions: 14 multiple choice questions, giving answers expressed as discontinuous variables on a nominal scale, and two other questions giving answers expressed as continuous variables on a interval scale. For the multiple choice questions, the subjects were asked to estimate the frequency of different symptoms on a five-point scale: $1=$ never; $2=$ less than once a week; $3=1-2$ nights a week; $4=3-5$ nights a week; $5=$ almost nightly/daily. For the other two questions, the subjects were asked to estimate the average time it took them to fall asleep in the evening and the average number of nocturnal awakenings. The questionnaire was translated and then back translated from Swedish to Dutch to enable it to be used in Antwerp. The number of subjects who completed the sleep questionnaire was 613, 724, 540 and 784 in Reykjavik, Uppsala, Göteborg and Antwerp, respectively (fig. 1).

\section{Sleep diary}

In Reykjavik, Uppsala and Göteborg, sleep habits were also investigated by means of a sleep diary of a type that has been used previously in studies in Iceland and Sweden $[11,22]$. The participants were instructed to make entries in the diary shortly after waking each morning. They used a broken line to indicate the time in bed before they fell asleep, and an unbroken line for the time they slept. Awakenings were shown by gaps in the unbroken line. The sleep diaries were analysed, using computerized digital analysis in Reykjavik [11, 22]. For each week, estimated total sleep time, time awake at night and sleep efficiency (sleep time divided by time spent in bed at night) was calculated from the diary. All the participants in Uppsala and Göteborg and a random sample of $25 \%$ of the participants in Reykjavik, and all of those with symptoms indicating asthma were asked to fill in the sleep diary. The number of subjects that completed the diary correctly was 166 in Reykjavik, 536 in Uppsala and 486 in Göteborg.

\section{Statistics}

The statistical analysis was performed with the Statistica 4.0 software package (StatSoft Inc, Tulsa, USA). The variation in the prevalence of sleep disturbances and sleep times in subjects with and without asthma was studied using the Chi-squared test and unpaired t-test. Correlations between single variables (sleep disturbances, symptom score, FEV1 and PEF variability) were studied with Spearman's rank correlation. The influence of combined variables on reported sleep and daytime disturbances (expressed as discontinuous variables on a nominal scale) was analysed using logistic regression analysis. The influence of combined variables on estimated sleep, time awake at night and sleep efficiency (expressed as continuous variables on an interval scale) was estimated using multiple linear regression. In order to obtain an approximate normal variation in the dependent variables, a $\log$ transformation $(\log (x+1))$ was performed on sleep latency and time awake at night. A p-value of less than 0.05 was regarded as statistically significant.

\section{Results}

\section{Asthma and sleep disturbances}

The demographic characteristics of the group of subjects with and without asthma is presented in table 1 . Subjects with asthma had a significantly higher prevalence of difficulties inducing sleep (DIS), early morning awakenings (EMA), snoring, self-reported apnoeas, daytime tiredness (feeling physically tired during daytime), daytime sleepiness (feeling drowsy in the daytime), higher number of nocturnal awakenings, longer

Table 1. - Characteristics of subjects with and without asthma

\begin{tabular}{lcc}
\hline & $\begin{array}{c}\text { No asthma } \\
(\mathrm{n}=2,394)\end{array}$ & $\begin{array}{c}\text { Asthma } \\
(\mathrm{n}=267)\end{array}$ \\
\hline Age yrs & $33 \pm 7$ & $33 \pm 7$ \\
Females \% & 54 & 55 \\
Smoker \% & 36 & 36 \\
BHR \% & 13 & $71^{* * * *}$ \\
Atopy \% & 31 & $67 * * *$ \\
Mite sensitization \% & 11 & $22^{* * *}$ \\
Allergic rhinitis \% & 28 & $71^{* * *}$ \\
Oral theophylline \% & 0.2 & $9.8^{* * *}$ \\
FEV1 \% pred & $107 \pm 12$ & $100 \pm 14^{* * *}$ \\
PEF variability \% & $4 \pm 3$ & $7 \pm 6^{* * *}$ \\
\hline
\end{tabular}

Values are presented as percentage or as mean \pm sD. BHR: bronchial hyperresponsiveness; FEV1: forced expiratory volume in one second; \% pred: percentage of predicted value; PEF: peak expiratory flow. $* * *: \mathrm{p}<0.001$, compared to subjects without asthma. 
Table 2. - The prevalence of sleep disturbance and sleep times in patients with and without asthma

\begin{tabular}{|c|c|c|}
\hline & $\begin{array}{l}\text { No asthma } \\
(\mathrm{n}=2,394)\end{array}$ & $\begin{array}{l}\text { Asthma } \\
(n=267)\end{array}$ \\
\hline $\begin{array}{l}\text { Difficulties inducing sleep } \\
\quad(\geq 3 \text { per week })\end{array}$ & 6.8 & $12.7 * * *$ \\
\hline $\begin{array}{l}\text { Early morning awakenings } \\
\quad(\geq 3 \text { per week) }\end{array}$ & 5.7 & $11.2 * * *$ \\
\hline Nightmares ( $\geq 1$ per week) & 5.0 & 5.7 \\
\hline Snoring ( $\geq 3$ per week) & 9.2 & $14.7 * *$ \\
\hline Apnoea ( $\geq 1$ per week) & 1.2 & $3.8 * * *$ \\
\hline Daytime tiredness ( $\geq 3$ per week) & 14.1 & $23.2 * * *$ \\
\hline Daytime sleepiness ( $\geq 3$ per week) & 16.0 & $26.8 * * *$ \\
\hline Sleep latency $\min$ & $19 \pm 23$ & $22 \pm 26 * *$ \\
\hline Nocturnal awakenings $\mathrm{n} \cdot$ night $^{-1}$ & $1.1 \pm 1.2$ & $1.6 \pm 1.6 * * *$ \\
\hline Total sleep time $\min$ & $450 \pm 80$ & $453 \pm 100$ \\
\hline Time awake at night $\min$ & $13 \pm 22$ & $15 \pm 22 * * *$ \\
\hline Sleep efficiency $\%$ & $96 \pm 6$ & $94 \pm 6^{* *}$ \\
\hline
\end{tabular}

Values are presented as percentage or as mean \pm SD. $* *: p<0.01$; $* * *: \quad p<0.001$, compared to subjects without asthma.

time awake at night and lower sleep efficiency than subjects without asthma (table 2). These associations were also found when populations from each centre were studied separately but the differences were not always statistically significant. The only exception to this was that in Uppsala no trend towards a higher prevalence of snoring was found in subjects with asthma compared to subjects without asthma.

Multiple logistic regression with adjustment for possible confounders showed independent associations between asthma and DIS, EMA, daytime tiredness, daytime sleepiness, snoring and apnoeas (table 3 and 4). When multiple linear regression was performed, asthma correlated weakly but significantly with sleep latency $(\mathrm{r}=0.05)$ and sleep efficiency $(\mathrm{r}=0.06)(\mathrm{p}<0.05)$.

In order to study whether the use of an enriched population sample may have biased the results, the multiple logistic regression analysis was repeated in the random sample. The odds ratios (95\% confidence interval) for the association between physician diagnosed asthma and night or daytime disturbances were: DIS 1.9 (0.963.7); EMA 2.6 (1.3-5.0); daytime sleepiness 1.7 (1.04-2.9); daytime tiredness $1.4(0.8-2.4)$; snoring 1.8 (0.9-3.3) and self reported apnoeas 5.8 (1.9-18).

\section{Asthma-related variables and sleep disturbances}

As expected, the group of subjects with asthma had a higher prevalence of BHR, atopy, sensitization to house
Table 4. - Multiple regression analysis of risk factors for self-reported snoring and apnoeas

\begin{tabular}{lll}
\hline & \multicolumn{1}{c}{ Snoring } & \multicolumn{1}{c}{ Apnoeas } \\
\hline Asthma & $1.7(1.2-2.5)^{* *}$ & $3.7(1.7-7.9)^{* * *}$ \\
Male & $2.4(1.8-3.3)^{* * *}$ & $3.2(1.5-6.7)^{* *}$ \\
Age $^{\dagger}$ & $1.7(1.4-2.2)^{* * *}$ & $1.9(1.2-3.2)^{* *}$ \\
Smoking & $1.2(0.9-1.6)$ & $1.9(0.98-3.6)$ \\
BMI $\geq 25 \mathrm{~kg} \cdot \mathrm{m}^{-2}$ & $2.2(1.6-2.9)^{* * *}$ & $1.2(0.6-2.4)$ \\
\hline
\end{tabular}

$\dagger$ : OR for increased risk of sleep disturbance for each $10 \mathrm{yr}$ increase in age. The values presented are odds ratio, and 95\% confidence interval in parenthesis, after adjustment for area of residence and all independent variables in the table. OR: odds ratio; BMI: body mass index. $* *$ : $\mathrm{p}<0.01$; $* * *$ : $\mathrm{p}<0.001$, for the relationship between the dependent and independent variables.

dust mite and allergic rhinitis, as well as lower FEV1 and higher PEF variability than subjects without asthma (table 1). Using univariate analysis, BHR was related to increased prevalence of daytime tiredness (20.2 vs $12.4 \%$, for those with BHR and without, respectively; $\mathrm{p}<0.001$ ), daytime sleepiness (21.7 vs $15.9 \%$; $\mathrm{p}<0.01$ ), EMA (8.8 vs 5.6\%; $\mathrm{p}<0.05)$, longer time awake at night $(15 \pm 22$ vs $12 \pm 22 \mathrm{~min})($ mean $\pm \mathrm{sD})(\mathrm{p}<0.01)$ and decreased sleep efficiency $(95 \pm 6$ vs $96 \pm 6 \%$; $\mathrm{p}<0.05)$. Allergic rhinitis was associated with increased prevalence of DIS (10.2 vs 6.1\%), daytime tiredness (18.7 vs 13.3\%), daytime sleepiness $(21.1 v s 15.2 \%)(\mathrm{p}<0.001)$, longer time awake at night $(16 \pm 27$ vs $12 \pm 19 \mathrm{~min})$ and decreased sleep efficiency $(95 \pm 7$ vs $96 \pm 6 \%)(\mathrm{p}<0.01)$. The use of theophylline was related to an increased prevalence of DIS $(22.6 v s 7.2 \%)(\mathrm{p}<0.001)$ and decreased sleep efficiency $(91 \pm 7$ vs $95 \pm 6 \%$; $<<0.01)$. FEV1 was negatively correlated with the daytime tiredness score $(\mathrm{r}=0.05$, $\mathrm{p}<0.05$ ), while PEF variability was positively correlated to time awake at night $(\mathrm{r}=0.10)(\mathrm{p}<0.001)$, and sleep efficiency $(\mathrm{r}=0.07)(\mathrm{p}<0.05)$. No significant association was found between atopy or mite sensitization and the quality of sleep.

Multiple logistic regression with adjustment for possible confounders showed an independent association between rhinitis and DIS, daytime tiredness and daytime sleepiness, while BHR was independently related to daytime tiredness (table 5). No significant association was found between snoring or apnoeas and any of the asthma-related variables. When multiple linear regression was performed, rhinitis correlated independently with time awake at night $(\mathrm{r}=0.07 ; \mathrm{p}<0.05)$ and sleep efficiency $(\mathrm{r}=0.09 ; \mathrm{p}<0.01)$. PEF variability correlated independently with time awake at night $(\mathrm{r}=0.07 ; \mathrm{p}<0.05)$.

Table 3. - Multiple regression analysis of risk factors for sleep disturbance and daytime symptoms

\begin{tabular}{llccc}
\hline & $\begin{array}{c}\text { Difficulties } \\
\text { inducing sleep }\end{array}$ & $\begin{array}{c}\text { Early morning } \\
\text { awakenings }\end{array}$ & $\begin{array}{c}\text { Daytime } \\
\text { sleepiness }\end{array}$ & $\begin{array}{c}\text { Daytime } \\
\text { tiredness }\end{array}$ \\
\hline Asthma & $1.8(1.2-2.7)^{* *}$ & $1.9(1.2-2.9)^{* *}$ & $1.5(1.1-2.1)^{* *}$ & $1.4(1.03-2.0)^{*}$ \\
Female & $1.0(0.7-1.4)$ & $1.0(0.7-1.4)$ & $1.7(1.4-2.1)^{* * *}$ & $1.8(1.4-2.3)^{* * *}$ \\
Age ${ }^{\dagger}$ & $1.2(0.9-1.5)$ & $2.0(1.6-2.6)^{* * *}$ & $0.7(0.6-0.8)^{* * *}$ & $0.9(0.8-1.1)$ \\
Smoking & $1.9(1.4-2.6)^{* * *}$ & $1.0(0.7-1.4)$ & $1.0(0.8-1.3)$ & $1.4(1.1-1.8)^{* *}$ \\
Snoring & $1.3(0.8-2.1)$ & $1.4(0.8-2.2)$ & $2.0(1.5-2.8)^{* * *}$ & $1.9(1.4-2.7)^{* * *}$ \\
Gastro-oesophageal reflux & $3.5(2.2-5.4)^{* * *}$ & $4.1(2.6-6.5)^{* * *}$ & $2.6(1.8-3.8)^{* * *}$ & $4.2(2.9-6.0)^{* * *}$ \\
BMI $\geq 25 \mathrm{~kg} \cdot \mathrm{m}^{-2}$ & $1.1(0.7-1.6)$ & $1.1(0.9-1.4)$ & $1.1(0.9-1.4)$ & $1.1(0.9-1.3)$ \\
\hline
\end{tabular}

$\dagger$ : OR for increased risk of sleep disturbance for each $10 \mathrm{yr}$ increase in age. The values presented are odds ratio, and $95 \%$ confidence interval in parenthesis, after adjustment for area of residence and all independent variables in the table. OR: odds ratio; BMI: body mass index. *: $\mathrm{p}<0.05$; **: $\mathrm{p}<0.01$; ***: $\mathrm{p}<0.001$, for the relationship between the dependent and independent variables. 
Table 5. - Multiple regression analysis of asthma-related risk factors for sleep disturbance and daytime symptoms

\begin{tabular}{lllll}
\hline & $\begin{array}{c}\text { Difficulties } \\
\text { inducing sleep }\end{array}$ & $\begin{array}{c}\text { Early morning } \\
\text { awakenings }\end{array}$ & $\begin{array}{c}\text { Daytime } \\
\text { sleepiness }\end{array}$ & $\begin{array}{c}\text { Daytime } \\
\text { tiredness }\end{array}$ \\
\hline BHR & $0.9(0.5-1.4)$ & $1.3(0.8-2.1)$ & $1.3(0.95-1.8)$ & $1.4(1.1-2.2)^{*}$ \\
Rhinitis & $2.0(1.4-2.9)^{* * *}$ & $1.4(0.9-2.0)$ & $1.3(1.04-1.8)^{*}$ & $1.4(1.05-1.9)^{*}$ \\
Theophylline & $2.5(0.7-9.6)$ & $2.5(0.6-10.0)$ & $1.9(0.6-6.0)$ & $0.2(0.02-1.7)$ \\
FEV1 \% pred ${ }^{\dagger}$ & $1.1(0.9-1.2)$ & $1.1(0.9-1.2)$ & $1.1(0.97-1.2)$ & $1.0(0.9-1.1)$ \\
\hline
\end{tabular}

$\dagger$ : OR for increased risk of sleep disturbance for each $10 \mathrm{yr}$ increase in age. The values presented are odds ratio, and $95 \%$ confidence interval in parenthesis, after adjustment for area of residence, gender, age, body mass index, reported snoring and gastrooesophageal reflux. For definitions see legend to table 1. *: p<0.05; ***: $\mathrm{p}<0.001$, for the relationship between the dependent and independent variables.

\section{Asthma-related symptoms}

A significant correlation was found between the number of asthma-related symptoms and the score for all sleep disturbance variables. Asthma symptoms score was also significantly correlated with sleep latency, time awake at night and sleep efficiency (table 6).

\section{Nonparticipants}

When comparing nonparticipants and participants in the randomly selected sample, it was found that in Antwerp the proportion of males who answered the sleep questionnaire was lower than in the sample who did not answer the questionnaire (43 vs 50\%; p<0.001). Mean age was slightly higher in subjects who answered the sleep questionnaire in Reykjavik (33 vs 32 yrs; $\mathrm{p}<0.05$ ) and Göteborg (34 vs 32 yrs; $\mathrm{p}<0.001)$ than among subjects who did not answer the questionnaire. In Uppsala the proportion of females ( 56 vs $45 \%$ ) was higher in the group who filled in the diary compared to the group who only completed the questionnaire. Mean age was slightly higher among participants in Göteborg and Reykjavik who filled in the sleep diary (34 vs 32 and 35 vs 33 yrs; $\mathrm{p}<0.01)$ compared to subjects who only answered the sleep questionnaire. In Göteborg there was a lower prevalence of nightmares ( $\geq 1$ per week) (6 vs 13\%) and early morning awakenings $(4$ vs $10 \%)(\mathrm{p}<0.05)$ in subjects

Table 6. - Associations between number of asthmarelated symptoms during the last 12 months and sleep disturbance and sleep times

\begin{tabular}{|c|c|c|c|c|}
\hline & \multirow[b]{2}{*}{$\begin{array}{c}\text { None } \\
(\mathrm{n}=1578)\end{array}$} & \multicolumn{3}{|c|}{ Symptoms } \\
\hline & & $\begin{array}{c}1 \\
(\mathrm{n}=562)\end{array}$ & $\begin{array}{c}2 \\
(n=293)\end{array}$ & $\begin{array}{c}3 \\
(\mathrm{n}=228)\end{array}$ \\
\hline DIS ( $\geq 3$ per week) & 4.7 & 9.5 & 12.3 & 14.0 \\
\hline EMA ( $\geq 3$ per week) & 4.4 & 6.6 & 10.2 & 13.3 \\
\hline Snoring ( $\geq 3$ per week) & 8.0 & 8.4 & 16.3 & 16.7 \\
\hline Apnoeas ( $\geq 1$ per week) & 1.2 & 1.3 & 2.4 & 2.7 \\
\hline $\begin{array}{l}\text { Day time tiredness } \\
\quad(\geq 3 \text { per week })\end{array}$ & 10.9 & 18.5 & 21.8 & 25.8 \\
\hline $\begin{array}{l}\text { Day time sleepiness } \\
\quad(\geq 3 \text { per week })\end{array}$ & 13.1 & 21.8 & 23.2 & 24.6 \\
\hline Sleep latency $\min$ & $16 \pm 18$ & $22 \pm 28$ & $25 \pm 30$ & $24 \pm 32$ \\
\hline Time awake at night $\min$ & $11 \pm 19$ & $15 \pm 28$ & $19 \pm 26$ & $14 \pm 18$ \\
\hline Sleep efficiency \% & $96 \pm 6$ & $95 \pm 7$ & $94 \pm 7$ & $94 \pm 6$ \\
\hline
\end{tabular}

Values are presented as percentage, or as mean \pm SD. DIS: difficulties inducing sleep; EMA: early morning awakenings. Asthma-related symptom score was significantly correlated with all listed variables $(\mathrm{p}<0.001)$. who filled in the diary than in those who did not. Otherwise there were no significant differences between subjects who answered both the diary and the questionnaire and those who only answered the questionnaire.

\section{Discussion}

In this study, we found that asthma is associated with a decreased quality of sleep. The prevalence of difficulties inducing sleep and early morning awakenings was about twice as high and the prevalence of daytime sleepiness $50 \%$ higher in asthmatic subjects compared to those without asthma. Asthmatic subjects as a group also had slightly lower sleep efficiency and a higher number of nocturnal awakenings than the rest of the population. In order to investigate the possible underlying mechanism causing impaired quality of sleep in asthmatic subjects, the association between asthmarelated variables and sleep disturbances was analysed. In the multivariate analysis, allergic rhinitis was found to be independently associated with DIS, daytime tiredness and daytime sleepiness, while BHR was associated only with daytime tiredness. Rhinitis and PEF variability were both weakly related to the time spent awake at night.

An increased prevalence of sleep disturbances in asthmatic subjects has been reported in other studies [9-12]. KLINK and QuAN [8], in a study from the Tucson Epidemiological Study of Chronic Lung Diseases, found that subjects with obstructive lung disease had more problems inducing and maintaining sleep and more daytime sleepiness than subjects without obstructive lung disease. However, when separating subjects with asthma from those with chronic bronchitis, no significant association was found between asthma alone and difficulties inducing and maintaining sleep or daytime sleepiness. GiSLASON and ALMQVisT [10] reported higher prevalence of difficulties maintaining sleep and daytime sleepiness in subjects with asthma or chronic bronchitis in a study of middle-aged men. In a previous study from one of our departments [11], hospital out-patients with asthma were compared with matched subjects without asthma from a population study. A higher prevalence of DIS, difficulties maintaining sleep and daytime sleepiness was found in patients with asthma in this study [11]. In the most recent general population-based study, FITZPATRICK et al. [12] found that asthmatic subjects reported less refreshing sleep than nonasthmatics. However, the authors found no difference in the prevalence of daytime sleepiness between asthmatics and nonasthmatics. 
Apart from the association of asthma with DIS, nocturnal and early morning awakenings, daytime sleepiness and daytime tiredness, we also found a higher prevalence of snoring and self-reported apnoeas among asthmatics than nonasthmatics. An increased prevalence of snoring among asthmatics has previously been reported by FITZPATRICK et al. [12]. Other studies have indicated possible associations between the obstructive sleep apnoea syndrome and nocturnal asthma [23, 24]. LiN and LIN [25] found an increased prevalence of BHR in 16 patients with obstructive sleep apnoea compared to a control group. They also reported a reduction in BHR after 2-3 months of continuous positive airway pressure (CPAP) treatment. In our study, however, we were unable to find an association between BHR and snoring or apnoeas.

We do not know of any previous epidemiological study that has investigated the relationship between allergic rhinitis and the quality of sleep. However, JUNIPER and GUYATT [26] found that many patients with allergic rhinitis experience sleep impairment during an allergy season, when they were developing a quality of life questionnaire for clinical trials. JUNIPER and co-workers [27] also showed that this sleep impairment could be reduced with regular treatment with topical corticosteroids. Increased nasal resistance may also be a contributing factor in the pathogenesis of obstructive sleep apnoea [28]. In our study, however, we found no significant association between allergic rhinitis and snoring or self-reported apnoeas.

Theophylline, which is chemically related to caffeine, has also been implicated as a possible factor in decreasing quality of sleep in asthma [29]. In the multivariate analysis, no significant association was found between the use of theophylline and the quality of sleep. As only $10 \%$ of the subjects with asthma used theophylline, the power to detect a significant relationship between the use of theophylline and impaired quality of sleep was, however, low in this study. No association was found between sensitization to house dust mite and the quality of sleep.

We have previously reported that in asthmatics subjective quality of sleep is related to disease activity [11]. In this study, we found a negative correlation between the number of asthma-related symptoms and quality of sleep. This result is in accordance with a recent study from Tucson, in which a significant relationship was found between the rates of respiratory symptoms and sleep complaints [30].

The definition of asthma used in this study was based on self-reported physician diagnosed asthma. This definition has been suggested by some investigators as optimal for epidemiological studies as it has a high specificity for clinical asthma [31]. In order to exclude subjects who had asthma only in childhood, only those individuals who reported having had asthma-related symptoms in the last 12 months were included. As adults over the age of $45 \mathrm{yrs}$ were not included, most of the problems of separating asthma from chronic obstructive pulmonary disease, were probably avoided.

In order to increase the number of asthmatic subjects in the study, an enriched population sample was used. Repeating the multiple logistic regression analysis in the randomly selected population, however, did not significantly alter the odds ratios for the association between asthma and sleep disturbances or daytime sleepiness. Therefore, we do not believe that the use of an enriched sample biased the results in this study. In the multivariate analysis, adjustments were made for those variables that we have previously found to be significantly related to sleep disturbances in a general population. Variables, such as seasonal variation or caffeine consumption, that were not previously found to be significantly related to the quality of sleep were, however, not included in the analysis [14, 15]. As in our previous reports, we found a strong association between reported nocturnal gastrooesophageal reflux (heartburn or belching after going to bed) and sleep disturbances.

The questionnaire used in this study is based on the Basic Nordic Sleep Questionnaire (BNSQ) [32]. The main change in the BNSQ compared to many earlier sleep questionnaires is the introduction of a five-point scale indicating how many nights/days per week symptoms occur. This facilitates comparisons when the questionnaire is used in different countries. This scale for quantifying subjective sleep complaints is now widelyused in the Nordic countries, as well as in some studies from other countries $[32,33]$. In this study, the use of three different languages carries the possibility of a translation bias. As we have reported from our previous analysis of the randomly selected sample, the variation in the prevalence of sleep disturbances between the two Swedish centres was, however, of the same magnitude as that between the Swedish and non-Swedish centres $[14,15]$. Therefore, we do not think that translation bias was a major problem in this study.

We conclude that asthma is associated with decreased subjective quality of sleep and increased daytime sleepiness. Concurrent allergic rhinitis may be an important underlying cause for sleep impairment in asthmatic patients. This study confirms the need to include questions about sleep characteristics in asthma questionnaires for clinical studies or quality of life assessment.

Acknowledgements: The authors thank E. Scholtes at the Department of Medicine, Uppsala University for assistance with the translation of the questionnaire to Dutch.

\section{References}

1. Boman G. Epidemiology of obstructive disease in the Nordic Countries. Eur Respir Rev 1991; 1: 316-320.

2. Björnsson E, Plaschke P, Norrman E, et al. A population-based study of symptoms related to asthma and chronic bronchitis in three areas of Sweden. Eur Respir J 1994; 7: 2146-2153.

3. Larsson L, Boëthius G, Uddenfeldt M. Differences in utilisation of asthma drugs between two neighbouring Swedish provinces: relation to prevalence of obstructive airway disease. Thorax 1994; 49: 41-49.

4. Clark TJH, Hetzel MR. Diurnal variation of asthma. $\mathrm{Br}$ J Dis Chest 1977; 71: 87-92.

5. Douglas NJ (Editorial). Nocturnal asthma. Thorax 1993; 48: 100-102.

6. Kales A, Beall GN, Bajor GF, Jacobson A, Kales JD. Sleep studies in asthmatic patients: relationship of attack to sleep stage and time of night. J Allergy 1968; 41: 164-173. 
7. Montplaisir J, Walsh J, Malo JL. Nocturnal asthma: features of attacks, sleep and breathing patterns. Am Rev Respir Dis 1982; 125: 18-22.

8. Fitzpatrick MF, Engleman H, Whyte KF, Deary IJ, Shapiro CM, Douglas NJ. Morbidity in nocturnal asthma: sleep quality and daytime cognitive performance. Thorax 1991; 46: 569-573.

9. Klink M, Quan SF. Prevalence of reported sleep disturbances in a general adult population and their relationship to obstructive airways disease. Chest 1987; 91: 540-546.

10. Gislason T, Almqvist M. Somatic diseases and sleep complaints. Acta Med Scand 1987; 222: 475-481.

11. Janson C, Gislason T, Boman G, Hetta J, Roos B-E. Sleep disturbances in patients with asthma. Respir Med 1990; 84: 37-42.

12. Fitzpatrick MF, Martin K, Fossey E, Shapiro CM, Elton RA, Douglas NJ. Snoring, asthma and sleep disturbances in Britain: a community-based survey. Eur Respir $J$ 1993; 6: 531-535.

13. Burney PGJ, Luczynska CM, Chinn S, Jarvis D. The European Community Respiratory Health Survey. Eur Respir J 1994; 7: 954-960.

14. Janson C, Gislason T, De Backer W, et al. Daytime sleepiness, snoring and gastroesophageal reflux among young adults in three European countries. J Intern Med 1995; 237: 277-285.

15. Janson C, Gislason T, De Backer W, et al. Prevalence of sleep disturbances among young adults in three European countries. Sleep 1995; 18: 589-597.

16. Burney PGJ, Laitinen LA, Pedrizet S, et al. Validity and repeatability of the IUATLD (1984) Bronchial Symptoms Questionnaire: an international comparison. Eur Respir J 1989; 2: 940-945

17. European Coal and Steel Community. Standardization of lung function tests. Clin Respir Phys 1983; 19 (Suppl. 5): $22-27$

18. Knox AJ, Wisniewski A, Cooper S, Tattersfield AE. A comparison of the Yan and a dosimeter method for methacholine challenge in experienced and inexperienced subjects. Eur Respir J 1991; 4: 497-502.

19. Björnsson E, Janson C, Håkansson L, Enander I, Venge P, Boman G. Serum eosinophil cationic protein in relation to bronchial asthma in a young Swedish population. Allergy 1994; 49: 730-736.
20. Janson C, Björnsson E, Hetta J, Boman G. Anxiety and depression in relation to respiratory symptoms and asthma. Am J Respir Crit Care Med 1994; 149: 930-934.

21. Higgins BG, Britton JR, Chinn S, Cooper S, Burney PGJ, Tattersfield AE. Comparison of bronchial reactivity and peak expiratory flow variability measurements for epidemiological studies. Am Rev Respir Dis 1992; 145: 588-593.

22. Gislason T, Reynisdóttir H, Kristbjarnarson H, Benediktsdóttir B. Sleep habits and sleep disturbances among the elderly: an epidemiological survey. J Intern Med 1993; 234: 31-39.

23. Guilleminault C, Quera-Salva MA, Powell N, et al. Nocturnal asthma: snoring, small pharynx and nasal CPAP. Eur Respir J 1988; 1: 902-907.

24. Shu Chan C, Woolcock AJ, Sullivan CE. Nocturnal asthma: role of snoring and obstructive sleep apnea. Am Rev Respir Dis 1988; 137: 1502-1504.

25. Lin CC, Lin CY. Obstructive sleep apnea syndrome and bronchial hyperreactivity. Lung 1995; 173: 117-126.

26. Juniper EF, Guyatt GH. Development and testing of a new measure of health status for clinical trials in rhinoconjunctivitis. Clin Exp Allergy 1991; 21: 77-83.

27. Juniper EF, Guyatt GH, O'Byrne PM, Viveiros M. Aqueous beclomethasone dipropionate nasal spray: regular versus "as required" use in the treatment of seasonal allergic rhinitis. J Allergy Clin Immunol 1990; 86: 380-386.

28. McNicholas WT, Tarlo S, Cole P, et al. Obstructive apneas during sleep in patients with seasonal allergic rhinitis. Am Rev Respir Dis 1982; 126: 625-628.

29. Rhind GB, Conaughton JJ, McFie J, Douglas NJ, Flenley DC. Sustained release choline theophyllinate in nocturnal asthma. Br Med J 1985; 291: 1605-1607.

30. Klink ME, Dodge R, Quan SF. The relation of sleep complaints to respiratory symptoms in a general population. Chest 1994; 105: 151-154.

31. Torén K, Brissman J, Järvholm B. Asthma and asthmalike symptoms in adults assessed by questionnaires: a literature review. Chest 1993; 104: 600-608.

32. Partinen M, Gislason T. Basic Nordic Sleep Questionnaire (BNSQ): a quantitated measure of subjective sleep complaints. J Sleep Res 1995; 4 (Suppl. 1): 150-155.

33. Young T, Palta M, Dempsey J, Skatrud J, Weber S, Badr S. The occurrence of sleep-disordered breathing among middle-aged adults. N Engl J Med 1993; 328: $1230-1235$ 